\title{
SABERES Y ANCLAJES DE LA ESCUELA INTERCULTURAL EN CONTEXTO MAPUCHE: SILENCIOS, INTERMITENCIAS Y ESTRATEGIAS EN LA TRANSMISIÓN DEL LEGADO HISTORICO
}

Knowledge and intercultural school anchorage in mapuche context: silence, flashing and strategies in the transmission of the historical legacy

\author{
Pilar Álvarez-Santullano*, Ana Alves** \\ Amílcar Forno*, Rita Rivera*, Pedro Fuenzalida*
}

Resumen

Metodológicamente, los resultados de los Talleres de Reflexión, puestos en práctica por los investigadores, ${ }^{1}$ muestran que los profesores no mapuches abren intersecciones discursivas en las que tienen cabida los conflictos mapuches, pero que luego tienden a volver sobre las prácticas y concepciones tradicionales de la educación intercultural. Por su parte, los docentes mapuches, suelen buscar alternativas para que saberes contextualizados en la reciente historia del pueblo mapuche, entren en circulación en el espacio de la escuela.

Palabras clave: Educación intercultural, saberes, dispositivo, performatividad.

Abstract

Methodologically, the results of the Reflection Workshops, placed into practice by the researchers, demonstrate that the non-mapuche professors open discursive intersections in which the mapuche conflicts can find a space, but that they later tend to go back to traditional conceptual practices of intercultural education. On their part, the mapuche professors tend to look for alternatives so that the contextualized knowledge in recent mapuche history, can enter into circulation in the spaces of the school.

Key words: Intercultural education, knowledges, dispositive, performativity.

\section{EL CONTEXTO DE LA INVESTIGACIÓN}

En la búsqueda de abrir nuevas posibilidades de construcción de la educación intercultural pusimos en juego los talleres de reflexión. ${ }^{2}$ Metodológicamente, nuestro intento iba por trabajar en una relación más horizontal entre los docentes de las escuelas con programas de educación intercultural y nosotros como investigadores. Se trata de un intento por trastocar las figuras de informante-investigador largamente construidas y

\footnotetext{
${ }^{1}$ Resultados del Proyecto Fondecyt N ${ }^{\circ} 1080420$ (2008-2011): "La inserción de saberes en el curriculum de la Interculturalidad como ruptura y continuidad con el espacio social mapuche huilliche".

${ }^{2}$ Los Talleres de Reflexión constituyen una de las modalidades metodológicas que son trabajadas en este Proyecto, en el que participan como colaboradores internacionales Ana Alves y Raúl Díaz, (Universidad del Comahue, Argentina). Las reuniones de trabajo sostenidas con ellos y con Gabriela Wuthrich han sido de gran importancia para abordar este artículo.
} 


\section{Pilar Álvarez-Santullano, Ana Alves, Amílcar Forno, Rita Rivera, Pedro Fuenzalida}

arraigadas fundamentalmente a través de entrevistas, relatos de vida y registros etnográficos, entre otras técnicas de investigación.

Los talleres nos han dado cuenta de las posiciones desde las que problematizan (o des-problematizan) los docentes mapuches y no mapuches la interculturalidad y, cómo tales posiciones, se relacionan con la selección de saberes mapuches y su tratamiento en el currículum. Tal vez no avanzamos mucho en una construcción de una educación intercultural que, según esperábamos, llegara a superar los enunciados "políticamente correctos" que actualmente conforman el discurso docente, aunque tal vez logramos que removiera - un poco, al menos - cierta comodidad asentada en tales enunciados. Abrir una duda o, al menos, una interrogante intermitente en los docentes no mapuches, y un espacio de interpelación de los docentes mapuches hacia la escuela, ha sido hasta ahora el resultado de nuestra tarea, de la que damos cuenta aquí.

Al poner en práctica los talleres de reflexión, nos centramos en el proceso de curricularización de los saberes mapuche-huilliche en escuelas que cuentan con programas de EIB. Nos interesa la selección e inserción de estos saberes en el currículum intercultural, en cuanto actúan como mecanismos de mediación que posibilitan la continuidad o ruptura de la escuela, con la trama política, social y cultural del espacio comunitario mapuche-huilliche, su inclusión/exclusión y, en consecuencia, como su tratamiento en la escuela tiene implicancias en la construcción del sujeto educativo. ${ }^{3}$ Poner la mirada en el campo de la escuela como lugar donde los saberes se movilizan, interconectan, y dialogan o conflictúan con otros saberes y conocimientos disciplinares implica abordarlos desde la dinámica y amplitud de sus redes constitutivas; esto es, no como saberes-recortes aislados, sino, por el contrario, como saberes a través de los cuales se construyen representaciones, como saberes que dicen algo acerca de alguien y que son hablados por alguien que ocupa una u otra posición en el espacio social $^{4}$ de la escuela donde se articula el campo educativo. ${ }^{5}$

\footnotetext{
${ }^{3}$ Sobre las implicaciones de los conocimientos en la construcción del sujeto educativo seguimos a Verónica Edwards (1986).

${ }^{4}$ Tomamos aquí el concepto de espacio social de Bourdieu (Giménez, 2010:13) para quien "el espacio social es un sistema de posiciones sociales que se definen las unas en relación con las otras (v., g., autoridad / súbdito; jefe / subordinado; patrón / empleado; hombre / mujer; rico / pobre; distinguido/ popular; etc.)".

5 "En las sociedades modernas caracterizadas por un alto grado de diferenciación y complejidad, el espacio social se torna multidimensional, y se presenta como un conjunto de campos relativamente autónomos, aunque articulados entre sí: campo económico, campo político, campo religioso, campo intelectual, etc. Un campo, por lo tanto, es una esfera de la vida social, que se ha ido autonomizando progresivamente a través de la historia, en torno a cierto tipo de relaciones sociales, de intereses y de recursos propios, diferentes a los de otros campos" (Giménez, 2010:14). En este artículo sólo hablaremos de los saberes mapuches en ese campo y de los actores involucrados. Lo que importa en esta nota es que un campo es más o menos autónomo, que se interrelaciona con otros campos y que se puede dar cuenta de éste en términos de relaciones sociales, de intereses y de recursos propios, diferentes a los de otros campos.
} 
Según Chervel, ${ }^{6}$ la escuela no es un espacio receptáculo de los subproductos culturales de la sociedad. Gvirtz et al. (s/f), agregan que la escuela no se reduce a un ámbito de reproducción de la cultura (que se produce fuera de ella), sino que se establece como un ámbito de práctica social diferente, con reglas y productos que les son propios en las llamadas prácticas discursivas escolares, ${ }^{7}$ entendidas como producciones discursivas de y en la escuela. Esta movilidad y rearticulación de los saberes no es, por supuesto, prerrogativa del espacio de la escuela. Gustafson, a propósito de su análisis de los saberes indígenas en la EIB, señala que "este saber es una memoria colectiva e histórica que se reproduce en el presente a través de redes de práctica social y política" (2004:2) y citando a Escobar (2001), agrega que el "saber indígena" se puede repensar y conceptuar "ya no construido en los términos de purezas cognitivas absolutas, sino en la forma de redes de articulaciones prácticas (simbólicas, sociales y políticas) que se entretejen con el ordenamiento de las relaciones entre los seres y sus entornos" (2004:9).

\section{LOS TALLERES COMO PRÁCTICA DE REFLEXIVIDAD}

Entender el conocimiento indígena como una red de práctica social, implica comprenderlo como "formas mediante las cuales el conocimiento se entrevera con las articulaciones de poder social y económico que cruzan cualquier contexto social - procesos que a veces se pierden de vista si nos mantenemos en la escuela enfocada en los circuitos mentales de los niños_-" Gustafson (2004:9). La escuela no puede reducirse y tener como norte sólo el desarrollo evolutivo y mental de los niños que la habitan. Es necesario entender que existen prácticas discursivas fuera y dentro de los espacios escolares, prácticas que hay que relevar desde modos de pensar autónomos y críticos respecto del poder-saber central.

Conforme a nuestro proyecto investigativo, la pedagogía en las escuelas de la interculturalidad no está marcada por una reflexividad crítica hacia la educación que permita, por ejemplo, repensar los saberes y prácticas escolares de la forma en que Gustafson y Gvirtz los plantean. Efectivamente, en nuestras visitas, profesores y docentes mapuches manifestaron que no hay tiempo disponible para intercambiar ideas en torno a sentidos y políticas de educación intercultural, y que, en general, los intercambios se reducen a delimitar tareas más inmediatas y específicas, constreñidas a incorporar contenidos mapuches en el contexto de clases planificadas previamente, de acuerdo con lo previsto en el currículum oficial; o bien, a una revisión o comentario por parte del maestro, de los contenidos y materiales que los "asesores culturales" (de ascendencia mapuche) elaboran para clases que realizan autónomamente, es decir, sin presencia de profesores de la escuela. Intentamos

\footnotetext{
${ }^{6}$ Citado en Gvirtz et al., s/f.

${ }^{7}$ Gvirtz et al., distinguen entre prácticas discursivas escolares, prácticas discursivas pedagógicas (como producciones discursivas sobre la escuela) y prácticas discursivas didácticas (producciones discursivas para la escuela).
} 
abordar esta carencia mediante la realización de talleres de reflexión, en el entendido de que a través de éstos, es posible acceder a una ruptura -0 , al menos, a una puesta entre paréntesis - con los enunciados que constituyen el sentido común ${ }^{8}$ que conforma el discurso de la educación intercultural de los maestros de las escuelas. Para ello, generamos espacios de interlocución, a los que invitamos a docentes huilliches y no huilliches, y asesores culturales (representantes de la comunidad encargados de enseñar saberes mapuches), y a los que concurrimos con nuestros propios discursos y posturas.

Las escuelas con programas de EIB incluyen ciertos contenidos, ciertos saberes mapuches comunes al currículum de las escuelas, legitimados por el tiempo y por discursos, homologados en las situaciones escolares, como saberes transmitidos antes que construidos en el aula (Edwards, 1986). Tales programas excluyen las posibilidades de ingreso de otros saberes que transitan por los bordes de la escuela, aquellos que se dicen esporádicamente y en ciertos lugares, o sobre los cuales opera el silencio; o bien se despliegan estrategias de acomodo curricular, de manera que no resulten problemáticos al interior de la escuela, ni en los vínculos de ésta con la comunidad que la constituye.

¿Qué conocimientos enseñan los docentes huilliches en el aula? Nuestras observaciones de aula, y las entrevistas previas a los talleres - realizadas a los docentes, a los directivos encargados de las escuelas y a los alumnos - dan cuenta de la prioridad que se le estatuye a la lengua mapuche. Se privilegian, en general, clases destinadas a enseñar vocabulario relativo al entorno, a los números y formas de saludo, en las que prima el conocimiento tópico, y el conocimiento como operación de la lengua. ${ }^{9}$

\footnotetext{
${ }^{8}$ A propósito del carácter reflexivo de la investigación, Angela Giglia cita la advertencia de Bourdieu respecto "de una práctica no reflexiva de la investigación, que por lo tanto no opere ninguna ruptura con el sentido común, y al contrario, se resuelva en una contribución a la reproducción de los prejuicios en boga sobre los fenómenos estudiados" (2003).

${ }^{9}$ Según Verónica Edwards: "En la escuela se transmiten y construyen, por lo menos, tres formas de conocimiento: la forma de conocimiento tópica, la forma de conocimiento como operación y la forma de conocimiento situacional". Respecto del conocimiento tópico, señala que éste "produce una configuración del contenido, cuyos elementos son datos que tienen sólo una relación de contigüidad y se presentan a través de términos más que de conceptos. Se trata siempre de datos que no admiten ambigüedades, y que pueden ser nombrados con precisión". La forma del conocimiento como operación "trata de la operación al interior de un sistema de conocimientos, por ej., usar las operaciones matemáticas al interior del sistema numérico. Usar la definición de las palabras homófonas, para clasificarlas, al interior del universo de las palabras". El tercer tipo de conocimiento, el situacional es "una forma de presentación del conocimiento, centrado en el punto de intersección entre el "mundo" y la mujer y el hombre, para el cual ese "mundo" es significativo. “(...) Otra dimensión constitutiva de esta forma de conocimiento, es ser presentado siempre como teniendo un valor intrínseco para el sujeto; valor intrínseco, en el sentido que le permita a éste ubicarse en el mundo. Ese mundo al cual el sujeto está, de todos modos, siempre interrogando para comprenderlo en relación a sí mismo y qué va significando. Es un conocimiento que se aprecia como sustantivo, en relación al proceso de autoconstrucción del sujeto (...)” (1986).
} 
En ocasiones, se constata el intento de docentes mapuches ${ }^{10}$ por presentar la enseñanza de su lengua como conocimiento situado

Para los Wetxipantü ${ }^{11}$ no se levanta bandera, se hace solamente así el tema mapuche (...) Claro, igual está el problema con el Estado, porque siempre tiene que andar adelante el tema del territorio, porque cuando uno le enseña cultura a los chicos, el mapuzugun tiene que enseñarse junto con el tema territorial, la cosmovisión igual, y siempre el tema del territorio. Por ejemplo, le hablaba yo a los chicos el tema del cerro (...), es muy ancestral en el kilchemapu, y ese cerro está en manos de un predio particular de un fundo. Entonces les decía: no podemos ir a visitarlo, sino que tenemos que mirarlo desde acá no más (E-DM-3). ${ }^{12}$

A propósito del acceso al cerro sagrado, el docente mapuche es interpelado por sus estudiantes: "tenían la interrogante ellos de cómo, porqué, quién lo quitó (...) yo les decía bueno... yo les comenté, porque tenía que comentarles lo que pasó (...)". Puesto en esta situación, decide narrarles la historia según la cual, los sitios sagrados mapuches quedan dentro de un fundo cercano a la escuela. La situación de despojo que narra el maestro a sus alumnos termina con hechos de violencia y muerte que conmueven a los alumnos

se alcanzó a salvar la lamgen, o sea la esposa de (...), entonces de ahí como que a los chicos les venía como una especie de rebeldía, otros de impotencia y otros que quedaban ahí pensando y pensando y se ponían a pensar. Entonces cuando les terminaba la historia quedaban pensando siempre, las niñitas quedaban mirando para arriba pensando y al final le cambiábamos el tema y ahí empezábamos a hacer otra cosa (E-DM-3).

Estos saberes son transmitidos en la comunidad. En ella, el docente escuchó desde niño esta historia; sin embargo, puestos en la escuela, estos saberes resultan problemáticos: "y [en] la comunidad decían que no les hablara mucho de esos temas así, entonces por eso yo obediente a mis peñis...". El docente directivo de la escuela, según relata nuestro entrevistado, reacciona también de manera similar

entonces un día me dijo que les enseñe más purrun, más mapuzugun a los chicos, que preparara algo para el fin de año, porque..., pero no me dijo que no enseñara eso, pero yo dije poco menos que para qué lado estaba apuntando más o menos, pero no, nunca me dijo nada en torno a eso, nunca, nunca (E-DM-3).

${ }^{10}$ Utilizamos el concepto de "docentes mapuches" para quienes ejercen docencia en el aula, indistintamente de si tienen o no título profesional. Ello incluye a los educadores tradicionales o asesores culturales, representantes comunitarios que enseñan saberes mapuches en el aula.

${ }^{11}$ Celebración mapuche del solsticio de invierno, se realiza el 24 de junio, o unos días antes o después de esta fecha.

${ }^{12}$ En la codificación, los símbolos empleados son los siguientes: E= Entrevista / TR= Taller de reflexión / $\mathrm{DM}=$ Docente mapuche $/ \mathrm{DD}=$ Docente directivo / Ant y $\mathrm{Ru}=$ Datos de establecimientos. 
En su relato, este docente mapuche nos cuenta que opta por callar, por excluir estos saberes del currículum escolar. Pese a que no explicita su desacuerdo con la inclusión de estos saberes, "sabe" que se le está pidiendo que no los trate en la escuela, y que se le advierte la conveniencia de volver a los saberes que se enseñan habitualmente en las escuelas con EIB.

A partir de este relato, y otros que nos indicaban que los docentes mapuches suelen generar estrategias de resistencia en la escuela, pensamos en la forma de abordar los talleres de reflexión, como una instancia para repensar los saberes ligados a la práctica, y contribuir a la deconstrucción y reconstrucción de los marcos de referencia que los sustentan.

\section{TALLERES Y DISPOSITIVOS}

Hay multiplicidad de enfoques prácticos y conceptuales de los talleres, como espacios de formación destinados al análisis de las prácticas docentes. Tales enfoques admiten un doble análisis: el del dispositivo explícito (sus objetivos, destinatarios y estilos de coordinación), y el análisis de los aspectos implícitos (supuestos teóricos sobre la formación y la intervención).

Respecto del taller como dispositivo explícito, mantuvimos el encuadre propio de ellos: desarrollo en pequeño grupo, con un coordinador externo, en un espacio-tiempo definido, y propusimos una tarea con pasos secuenciados (Vera Godoy, 1985). En el intento de suscitar una reflexión sobre el abordaje y el sentido de la inclusión de saberes mapuches en el currículum, seleccionamos algunos textos y un video, que nos permitieran provocar el diálogo con miras a revisar, discutir, deconstruir el currículum colonizador que las escuelas han venido asumiendo sin mayor problematización, para la EIB.

Comenzamos la experiencia realizando un taller interno en cada una de cuatro escuelas con EIB de la provincia de Valdivia. Como actividad preparatoria, o introductoria, entregamos previamente al taller de cada escuela el texto "La formación de los docentes: interrogantes y desafíos de nuestro tiempo", de Alejandra Birgin (2006), de manera que pudieran leerlo y comentarlo entre ellos. Si así no había ocurrido, en la fase de desarrollo comentamos una selección del texto. Posteriormente, se trabajó con el registro en video de "El engaño", una obra elaborada por una profesora mapuche, y con los niños y niñas de su escuela, que fue representada durante un Wetxipantu. Finalmente, leímos parte de una entrevista a una asesora cultural. ${ }^{13}$ Todos estos textos (escritos y videos) tenían como función actuar como dispositivos, como elementos estratégicos destinados a permitir que los docentes explicitaran los discursos con que sustentan la educación intercultural, los contrastaran con los textos presentados, buscando analogías y puntos de tensión y, lo

\footnotetext{
${ }^{13} \mathrm{Al}$ final del taller entregamos a cada uno de los docentes parte de un capítulo sobre Planificación de enseñanza como estrategia de política cultural, para ser leída, previamente, al próximo taller que realizamos en conjunto con las tres escuelas más cercanas entre sí.
} 
que es más importante, que se generara entre docentes mapuches y no mapuches (investigadores incluidos), un espacio de escucha mutua y de reflexión que posibilitara la emergencia de otras construcciones, distintas y eventualmente opuestas a los discursos que hegemonizan el campo de la educación intercultural.

\section{LA LECTURA DEL TEXTO DE BIRGIN}

Este texto nos interesó particularmente porque contiene la narración de la genealogía de una película camboyana La gente del Arrozal ${ }^{14}$ y, esperábamos, que los docentes la relacionaran con la enseñanza de saberes mapuches. Un concepto clave, implícito en la cinta, era el de "legado", del que, según Birgin, la escuela debe hacerse cargo

Somos depositarios y pasadores de un legado, pero el modo de pasarlo tiene que permitir el cuestionamiento de eso que enseñamos o queremos legar. Y ese cuestionamiento de aquello que pasamos tiene que dar lugar a lo nuevo. Tenemos que dar lugar a que otros lo piensen, lo imaginen, produzcan eso de otra historia, su historia. En este sentido, educar consiste en la compleja tarea de pasar un legado y, a su vez, dar lugar a la diferencia" (2006:8).

Como se advierte, el legado constituye un elemento que demanda nuevas elaboraciones, es base fundante que dinamiza la identidad, en vez de esencializarla, como ocurre en los discursos pedagógicos sobre la interculturalidad, que operan sobre la base del rescate de una cultura de antaño. La pregunta que promovimos a partir de

\footnotetext{
${ }^{14}$ Birgin (2006) la narra de esta forma: "[La película] Cuenta la vida de los camboyanos, quienes vivían una vida campesina alrededor del cultivo del arroz. Al llegar la dictadura de los '70, arrasa con 6.000.000 de personas y, además, inutiliza el conjunto de los campos. Rithy Panh, el director del filme, cuyos cinco hermanos fueron hacinados en los campos de concentración de Camboya, mientras que él logra que un organismo internacional lo rescate para terminar residiendo en París. Pero, cuando su país recobra su institucionalidad, Rihty Panh regresa a Camboya y al visitar una escuela, pregunta a los chicos de dónde viene el arroz que están comiendo. Ellos le contestan que el arroz llega con los "camiones de UNICEF". Ahí es cuando Rithy Panh decide volver a París y filmar "La gente del arrozal". Pero no lo hace con el espíritu de que Camboya vuelva a cultivar el arroz, como lo hacía en los cuarenta o cincuenta; lo hace con la convicción de que todos esos chicos tenían que saber que el arrozal era el modo de producción alrededor del cual vivían sus abuelos; que ese era el modo en que estaban explotados los campos que hoy están inutilizados para el cultivo. En otras palabras, aquello que lo inquietaba era proponer una vía para reponer una parte de la historia de Camboya que estaba ausente en la memoria de los chicos. Pero no se trata de hacer esto para que todo vuelva a ser lo que era, no es posible, porque ni el arroz tiene el mismo lugar en el mundo, ni la tierra está en condiciones de volver a sembrar arroz, ni las familias son las que eran. Pero sí tiene una preocupación por decir: "De acá venimos". Y los chicos tienen derecho a saber que el arroz no viene del camión de UNICEF porque sí. El camión de UNICEF lo trae porque hubo una guerra que arrasó con los camboyanos, con sus producciones. En este sentido, la transmisión también tiene que ver con cómo reponer lazos entre generaciones. Entre generaciones que en muchos casos han visto interrumpida la posibilidad de recibir un legado".
} 


\section{Pilar Álvarez-Santullano, Ana Alves, Amílcar Forno, Rita Rivera, Pedro Fuenzalida}

esta lectura era: “¿Por qué resulta importante que los niños camboyanos sepan la historia de los arrozales?".

La reacción a la historia de los arrozales nos permite, por una parte, advertir los cambios de posición discursiva que ocurren en quienes hablan desde su identidad docente. En una primera instancia, hay una tendencia a leer en el texto de los arrozales algo de su propio discurso pedagógico, enfatizando la importancia de la contextualización del aprendizaje, de la pertinencia

Fíjese que antes, por ejemplo, había la siguiente situación: nos enseñaban lo que era la historia de Egipto, la historia de (...) de Grecia, de Roma, y ni siquiera conocíamos la historia de nuestro entorno. Entonces, ahora está más contextualizado el aprendizaje. A partir de nuestro entorno vamos generando y nos vamos abriendo hacia fuera. Entonces eso hay que rescatarlo (TR-Ant-1).

A partir de la necesidad de contextualizar los aprendizajes, emerge el discurso del rescate de la cultura mapuche, que persiste a lo largo del taller. Se construye la EIB como intervención salvadora - "para que no se pierda la cultura mapuche", para recuperar "los valores perdidos" - tópico constituyente del discurso sacralizado de la EIB, que se asocia con el reforzamiento de la identidad y el mejoramiento de la autoestima del niño mapuche. El discurso del rescate sugiere, ya, un lugar de habla de la dominancia: quien rescata está en una posición segura, un lugar fijo que le permite actuar sobre el otro, quien a su vez, está en situación de amenaza, de pérdida, de minusvalía. La educación intercultural, como rescate, sitúa a la escuela en un lugar de privilegio "visionario" frente a quienes no han sabido — y aún no saben — resguardar lo propio, lo esencial que los constituye en su identidad.

Ante la persistencia del discurso del rescate, sugerimos - e hicimos - una lectura ahora presencial del episodio de los arrozales, para ver si surgían nuevos constructos. A partir de esta nueva lectura, e interpelados por uno de los investigadores sobre la posibilidad de dar cuenta en la educación, de la génesis histórica de los conflictos actuales en los territorios mapuches, un docente directivo trasciende el plano pedagógico, reconstruye su posicionamiento y abre la posibilidad para incorporar la historia como conocimiento situado

Si hoy día pensamos, cómo el pueblo mapuche perdió sus tierras - y hoy día están en el ámbito de poder rescatar algunas a través de CONADIpara poder volver a poseerlas, claro que sí, es importante que conozcan cómo perdieron sus tierras y por qué está luchando hoy día el pueblo mapuche para restaurar esa situación, de alguna manera. No porque sí no más, no porque ellos quieran tener tierras, no, que ellos sepan que en un tiempo pasado las tierras les fueron usurpadas (...) (TR-Ant-1).

Abierto este cauce, los maestros no mapuches confirman su saber de la historia local, saber entretejido en las prácticas conversacionales en la comunidad, oídas de un antiguo mapuche, con el cual "nos sentamos así en un tronco grande que había afuera de su casa", o en el contexto familiar: "el abuelo de mi señora que 
trabajó más de cincuenta años en la familia (...) y él hablaba de eso". Éste es un momento de emergencia de historias locales de despojo y de violencia, que circulan por fuera de la escuela, de las cuales se concluye

Entonces eso habla de cómo la gente se fue haciendo de tierras y es por eso que hoy día la gente también está haciendo trámites de alguna manera para poder recuperar lo que se fue. Entonces, conociendo esas cosas y cuando el niño sabe cómo perdieron lo que ellos tenían, lógico que ahora tiene sentido empezar a valorizarse, a cambiar su actitud, porque ellos no son cualquier persona, traen una historia detrás (TR-Ant-1).

Una docente problematiza en el plano concreto el planteamiento anterior

Como dijo el colega "cuando el niño sabe". Pero ¿Sabrán los niños? (...) porque uno a veces conversa con los chicos (...) conversamos, pero nunca, nunca se ha tocado ese tema, o sea, no sé si los más chicos míos saben, no sé si los de séptimo u octavo ellos sabrán, pero yo noto que los míos no..., no (TRAnt-1).

"Nunca hemos conversado temas de ese tipo", ratifica el docente. Y ante la pregunta respecto de la responsabilidad que le cabe a la escuela sobre estos saberes, retorna al plano pedagógico del discurso, mediante una aproximación históricodemográfica de los asentamientos poblacionales, como base de inserción de los saberes locales, afirmándose en lo disciplinario, filtra y minoriza todo rastro de conflicto:

Bueno, por eso que, en alguna manera, lo que nosotros queremos hoy día está en el proyecto que tenemos en desarrollo, que tiene la finalidad que los chicos conozcan cómo llegó a poblarse este lugar, el asentamiento humano que hubo acá en este sector, para que ellos conozcan cuáles son... cómo llegaron aquí, de dónde venía la familia, cuáles fueron los troncales..., las familias troncales (TR-Ant-1).

El hilo discursivo sobre saberes situados desarrollado por los maestros no mapuches no es lineal, se lee a ratos con el lente del discurso pedagógico de la pertinencia, se entronca al discurso del rescate cultural, y se desborda cuando la memoria trae a presencia la narración comunitaria de la injusticia, y vuelve al deber ser de la escuela anclada en el circuito de los proyectos tecnocráticamente formateados. De esta forma, los maestros y maestras van asumiendo, intermitentemente, posturas críticas y reflexivas en relación a la EIB. Podríamos decir, con Nieves Blanco, que: "Tal vez la naturaleza de los cambios educativos es la intermitencia, lo que significa que necesitan 'reabrirse' de manera permanente, y sólo lo puede hacer cada maestra y cada maestro en primera persona, es decir, teniendo en cuenta su experiencia y en sus circunstancias concretas, que siempre cambian” (2005:375). 


\section{Pilar Álvarez-Santullano, Ana Alves, Amílcar Forno, Rita Rivera, Pedro Fuenzalida}

Por otra parte, en general, los docentes mapuches se mantienen en silencio frente a la historia narrada de los arrozales, pero también se produce un reconocimiento de la propia situación

Ahí uno puede asimilar... (...) Por qué ahora el pueblo mapuche tiene que estar peleando por las tierras, si antes tenían las tierras a su disposición. Uno puede hacer esa comparación, por qué sucedió eso. Porque ahora el problema prácticamente es por el territorio que se lucha (TR-Ant-1).

A propósito del legado en la educación, y situada en la historia de Argentina, señala Birgin: "Y hay temas de los cuales de un modo o de otro no se habla, y tiene que ver también con la dificultad de la transmisión" (9). Y, efectivamente, luego de reconocerse como sujeto que forma parte de una historia colectiva, semejante a la de los arrozales, un docente mapuche explicita el reclamo por los silencios del currículum de la interculturalidad

(..) En el currículum, generalmente, en los textos siempre se omite información. Por ejemplo, se habla del pueblo mapuche como que 'existían'.

La historia de Chile se cuenta de una manera, no como realmente es. En la historia de Chile cuentan todo muy bonito, los héroes mapuches, Caupolicán, Lautaro, hasta lo que hicieron, pero no el sufrimiento de las familias, [lo] qué pasó..." (...) Escrita por los cronistas, historiadores, y generalmente, la realidad no es así, no era así. Por ejemplo, los cronistas, historiadores, hablaban de los mapuches como seres bárbaros, salvajes, sin cultura y ahí uno se da cuenta también que la historia de Chile no es como se cuenta. (TR-Pi-1)

Esta amnesia del currículum puede explicarse y comprenderse desde el tratamiento que las sociedades le otorgan a sus eventos históricos traumáticos. $\mathrm{Al}$ respecto, Carretero señala que "En un presente donde los conflictos pasados se mantienen irresueltos y pueden hacer peligrar un futuro que se avizora como prometedor, el pasado tenderá a recuperarse en forma conciliatoria. En este caso, las sociedades facilitan la tramitación del "silencio" o el "olvido" transitorio sobre los eventos traumáticos y, evidentemente, el rol de la escuela se vuelve primordial para asegurar estos objetivos" (2010:105).

Comentarios metodológicos. ${ }^{15}$ El texto de Birgin fue una apuesta metodológica que condujo a la emergencia en escena de los problemas, conocimientos y discusiones sobre la propia práctica de los docentes. Esta metodología pudiera tener un aspecto discutible, en el sentido de que la selección previa de textos puestos al comienzo pone en evidencia el predominio de nuestra lógica académica por sobre la práctica y los

\footnotetext{
${ }^{15}$ Al final del trabajo con cada dispositivo utilizado en los Talleres de Reflexión, se incluyen comentarios metodológicos, tanto por la necesidad de revisar nuestras propias prácticas, como por el interés que pudieran tener para experiencias similares.
} 
saberes de los profesores. No obstante, la historia de los arrozales se constituyó en un aporte teórico que implicó trabajar algunos conceptos, como el de transmisión escolar, expresado en Birgin, y funcionó como posibilitador de diálogo y discusión en el contexto escolar, donde los espacios de disenso no son habituales. El texto nos permitió, además de abrir el juego, poner en evidencia cuáles eran nuestras posiciones como investigadores-coordinadores, así como conocer y problematizar las posiciones de los docentes del taller.

\section{LA REPRESENTACIÓN DE LA HISTORIA EN UNA OBRA DE TEATRO ESCOLAR}

Un segundo dispositivo empleado en estos talleres fue un video obtenido de la representación escolar El Engaño. La autora, una profesora mapuche de educación básica, cuenta que la obra fue hecha para mostrar, como hecho central, lo que ocurrió con las ventas fraudulentas de tierras

y se les contó la parte de las tierras, por qué finalmente las familias mapuches fueron quedando en espacios tan chiquititos, cuando en realidad ellos tenían grandes hectáreas de terreno y finalmente nos fueron amontonando a todos en sectores, en pequeñas parcelitas donde apenas entraba la casa, ni siquiera hay espacio para hacer una huerta, cultivo de papas, de maíz, de porotos, lo que se hacía antes y de ahí partió de los mismos chicos preguntando por qué se vendía tanta tierra, por qué sus abuelos fueron perdiendo las tierras, por qué cuando venía gente occidental les quitaban la tierra simplemente, quién regulaba eso y por qué no les pagaban como debería ser... (TR-Ant-2).

El momento decisivo de la experiencia narrada ocurre cuando los niños asumen la tarea de hacer la obra, por cuanto la identidad se asume no solamente como modo de ser o sentir, sino que se construye performativamente, en el hacer

Los chicos mismos dijeron: tía, hagamos esto porque nadie lo conoce, nadie lo ha hecho y siempre muestran la otra parte que dicen que los mapuches somos malos, que los mapuches somos peleadores, que los mapuches alegamos sin tener razón y además que somos sucios, pobres, y un montón de cosas negativas que ellos dijeron que no: contemos la verdad, lo que pasó (TR-Ant-2).

De este modo se revela que todo contenido o saber se vuelve inseparable de la práctica misma, y la praxis es acción emancipadora, que posibilita — según Piaget y Kohlberg, (Antón Valero, 2003) — "una reconstrucción de la autonomía moral como fin educativo, a partir de problemas y conflictos concretos, situados en contextos sociohistóricos que permiten una autonomía intelectual (...)”. En este ejercicio del derecho de los niños para relatar su versión de la historia, los saberes hegemónicos posicionados en el espacio del aula son desmontados, deconstruidos $\mathrm{y}$, puestos en escena en una perspectiva antinómica, reveladora de "la otra verdad", 


\section{Pilar Álvarez-Santullano, Ana Alves, Amílcar Forno, Rita Rivera, Pedro Fuenzalida}

esa del saber comunitario y confidencial que no ha circulado por los espacios oficiales de lo público

Llegaban fascinados contando "tía, sí, mi abuelo dijo tal cosa y es lo mismo que usted nos contaba y en ese cerro pasó tal cosa y ellos dijeron que era verdad y que así se fue transmitiendo, que traten de que no se cuente más allá porque — como se le llama entre comillas — los Winkas, eh..., ellos se enojan cuando uno habla de eso, así es que tienen que no publicarlo tanto". Y yo les dije que no, que si ellos realmente querían conocer y sentirse mapuche tenían que saber cómo fueron las cosas en la realidad (TR-Ant-2).

La alianza del saber que se produce con los niños y niñas (en la que entra también la comunidad), y la atenuación de la denuncia mediante el humor, constituyen respectivamente el respaldo y la estrategia que le permiten a esta docente, enfrentar las dudas que señalan los demás profesores de la escuela, respecto de la conveniencia de incorporar - en el espacio escolar - el tema de la adquisición fraudulenta de tierras, pero, finalmente logra un acuerdo

Al principio tuvimos unos pequeños inconvenientes para poder presentar esta obra eh..., con los mismos colegas de la escuela, ellos decían que no, que no presentáramos algo así porque íbamos a entrar en conflicto con la gente de la comunidad o con el público presente o con algunas autoridades... (TR-Ant-2).

Entonces yo les dije si presentábamos la obra teníamos que hacer como una introducción que fuera contundente, pero que no ofendiera a nadie. Y yo les dije: "Yo confío en la gente de acá de la comunidad, confío en mi gente y yo sé que ellos no van a poner conflicto porque los chicos hagan esta obra $-\mathrm{y}$ les dije- - es más, yo les apuesto que se van a divertir, que lo van a pasar bien y es más, los va a llevar a reflexionar por qué ocurrió eso, por qué permitimos que pasara esto", y finalmente terminamos convenciéndolos, pusimos la obra en el acto (...)" (TR-Ant-2)

El salto del discurso oculto ${ }^{16}$ de la comunidad al espacio público en la escuela es posible si se cuenta con un respaldo y con una estrategia adecuada. Según Scott, "Como los editores prudentes de un periódico de oposición en una situación de estricta censura, los grupos subordinados tienen que encontrar maneras de transmitir su mensaje manteniéndose como puedan dentro de los límites de la ley" (2003:200). La representación escolar, donde maestros y apoderados aplauden la obra y el trabajo de sus niños, es un ámbito adecuado para introducir lo que puede alterar el orden establecido, y abre la expectativa de lo prescrito como discurso tradicional escolar. ${ }^{17}$

\footnotetext{
${ }^{16}$ Scott (2003) reconoce un discurso público y otro oculto, tanto en los grupos subordinados, como en los dominantes.

${ }^{17}$ Contribuye también en ello el humor de la representación y del guión de la obra: el primero, producido por equívocos de los niños en el escenario (olvidos del guión o errores de desplazamientos en el escenario, entre otros), y el segundo, porque pone en juego exageraciones o hipérboles y utiliza la parodia ("son carretas que vuelan" tiene que explicarle un mapuche a otro que
} 
La puesta en escena abre la reflexión entre los miembros de la comunidad, y posibilidades de reconocimiento, aunque todavía a prueba, en los demás maestros $\mathrm{M} / \mathrm{NM} / \mathrm{AC}$

(...) y después ocurrió todo lo contrario en vez de ocurrir conflictos llegaron a felicitarnos, felicitaron a los chicos que lo habían hecho muy bien y que habían entendido el sentido de lo que significaba haber cometido un error y haber dejado que esto pasara en las comunidades. Así que después [los profesores] me decían "bueno esta vez tuviste suerte, no generó conflicto en nada" y yo decía "pero si uno hace que los chicos entiendan el sentido de cada cosa que se le enseña, no tiene por qué generar conflicto (...) (TR-Ant-2).

La proyección del video produce en los docentes mapuches el reconocimiento y la solidaridad frente a la situación planteada, a través de una puesta en escena. Reconocen en la comedia, realidades que ocurrieron y que ocurren actualmente; expresan su conformidad y evalúan como muy bien expuesta la situación de despojo, y las fórmulas usadas para concretarlo. "(...) El licor es uno de los métodos que usaron, la religión fue otro de los métodos, ehm... el engaño... y com... también comprando las autoridades, como siempre ocurrió. Siempre el dinero ha sido una de las fórmulas que..., un método que ha usado constantemente el no mapuche para adquirir su... su... o cumplir sus propósitos, digamos, en este caso. (...)" (TR-Ant-2). En cambio, entre los docentes no mapuches, la reacción sólo apunta a resaltar una mirada más neutra, enfatizando sólo las posibilidades didácticas del teatro escolar: (...) "Hay una... una instancia a través del teatro también como para enseñarle un poquito los valores, el respeto por los mayores ¿Ya?”' (TR-Ant-2).

\section{COMENTARIOS METODOLÓGICOS}

El video hizo posible no sólo la discusión acerca de los contenidos mapuches sino, también, discutir el modo como son incorporados en la enseñanza. Aunque en el taller no se contempló la posibilidad de partir, primeramente, escuchando relatos sobre experiencias de los participantes, poner en juego una metodología más "innovadora", impulsada por un par en contexto similar, disparó la reflexión acerca de la realidad en la que están involucrados y la forma en que la miran, la piensan y actúan sobre ella. Lo que se ve y se piensa incide sobre el hacer. Revisar la cuota de significación personal, nos permite entender por qué percibimos de la manera que percibimos (Vera, 2008).

no sabe qué es un avión) con lo cual se distiende al auditorio. La atención focalizada en el humor, atenúa el impacto de la representación del despojo de tierras y de situaciones conflictivas que están ocurriendo en la misma comunidad, como cuando en el cierre de la obra cada uno de los tres personajes winkas, que luego del engaño son ahora los propietarios de las tierras, comentan que levantarán un edificio, una casa gigante y, el tercero, una hidroeléctrica. Esta última alusión remite precisamente al punto de mayor conflicto actual en la zona, problemática eludida por la escuela como tema de estudio, análisis o discusión. 
Podríamos decir que el dispositivo opera en pro de una generalización de la memoria: "lo que ocurre en otra escuela ocurre también en mi escuela". El video permitió a los maestros mapuches, retomar la narración de su propia historia. En definitiva, esta modalidad de trabajo generó más solidaridades y menos pudor para expresar los deseos de ruptura con lo establecido, con el currículum predeterminado.

\section{UNA ENTREVISTA A UNA DOCENTE MAPUCHE}

La entrevista a una asesora cultural, recogida en un Proyecto Fondecyt anterior, ${ }^{18}$ constituyó el tercer dispositivo que trabajamos en los talleres. La entrevista — valiosa por los variados planteamientos sobre la educación intercultural, y los múltiples sentidos que abre la docente sobre la EIB - nos interesó particularmente por dos aspectos. El primero de ellos, porque su discurso sobre educación intercultural dialoga con el concepto de legado incluido en el texto de los arrozales

como que uno quería que los chiquillos aprendieran y quería que ellos tuvieran esas ganas, esa fuerza, que ellos supieran quiénes somos de dónde venimos y qué es lo que queremos realmente para nosotros como mapuches, como pueblo: qué es lo que queremos (E-DM-5).

El otro aspecto, es la continua interpelación que hace la entrevistada a quienes no son mapuches, lo que permite generar transferencias y reflexividad a partir de contextos diferentes, pero marcados por las mismas experiencias de despojo y de discriminación. Destacamos dos momentos en los que se refiere a la discriminación y al discurso de la tolerancia en la EIB

Y nunca — si bien es cierto dicen, hay que rescatar la cultura, la lengua, la forma de vestirse, la forma de comer, muchas cosas - pero si llega una persona con ojotas, con mantas y todo ¿Son capaces de atenderla como atienden al resto? No, porque yo esa discriminación la viví, hace un año atrás (E-DM-5).

$\mathrm{Al}$ respecto, la entrevistada refiere una dolorosa experiencia personal, cuando a su abuelo no le permiten ingresar, tras larga espera, a un hospital a ver a su esposa enferma debido a su vestimenta y — como dice la misma narradora, situándose en el lugar de habla winka - "porque sus pies llevan microbios y porque la manta es de indio y también lleva microbios". A partir de esta experiencia, pone en cuestión el discurso de la tolerancia que la educación intercultural dice valorizar y promover

es ahí cuando uno pregunta ¿Realmente toleramos al mapuche? Nunca lo van a hacer, hay mucha gente que está preparada, sí, y que de corazón acepta y le gusta, pero no todos. Entonces enseñarle a los chicos que ellos pueden hablar su lengua, pueden hacer su ceremonia libremente, pueden vestirse libremente, con orgullo y todo lo demás, pero para ellos, para su

\footnotetext{
${ }^{18}$ Fondecyt $N^{\circ} 1050634$ (2005-2007).
} 
pueblo, y sin pensar que todo es color de rosa y que en todas partes los van a aceptar (E-DM-5). ${ }^{19}$

Frente al relato de la discriminación sufrida en el hospital, tanto los docentes mapuches como no mapuches, en general, empatizaron con la entrevistada. Sin embargo, hubo un docente directivo que cuestionó varios aspectos, cuyo análisis puede representar posturas vigentes, aunque generalmente no explicitadas por el profesorado.

El docente directivo cuestiona el reconocimiento del pueblo mapuche y la multiculturalidad como imaginario posible de la convivencia nacional

...Por qué siempre que hablamos de EIB, hablamos como de dos mundos... dos pueblos, en consecuencia que ya llevamos prácticamente más de doscientos años conviviendo juntos y mezclándonos y volviéndonos a mezclar... (TR-Ru-1).

La genealogía de tal argumentación, parece provenir de una mirada simplificada y esencialista y racial del concepto de cultura, y de planteamientos de la historia que se entregan en los niveles de enseñanza básica y media, los que sitúan la nacionalidad chilena, como producto que emerge de la mezcla de indígenas y españoles

"Como que me parece a mí también un poco.... hablar del pueblo mapuche y del pueblo chileno, como dos pueblos totalmente diferentes en consecuencia que yo preferiría hablar de los chilenos, o sea, del pueblo de Chile" (TR-Ru-1).

El director sustenta la unidad racial y cultural de la nación chilena, y desde su posición de poder-saber se sitúa como ejemplo, y objeta a la asesora cultural, vulnerando con ello el sentido del trabajo de ésta en la escuela

“...porque acá ipucha! no porque [la educadora] tenga dos apellidos mapuches ella me va a decir que es netamente mapuche ${ }^{20}$ usted ya sabe que el mestizaje ya se hizo global, entonces yo puedo tener un montón de sangre mapuche a pesar de que no tengo ningún apellido mapuche, entonces de qué pueblo me puedo considerar yo viviendo en estos años, viviendo mi padre, mi abuelo, bisabuelos, todos aquí en Chile" (TR-Ru-1).

\footnotetext{
${ }^{19}$ La entrevistada advierte sobre el fracaso del discurso de la tolerancia en la educación intercultural ("nunca lo van a hacer"). De hecho, distingue entre un espacio cultural íntimo, el de la comunidad, espacio libre de tensiones emergentes de situaciones de dominación y discriminación, para el que la escuela enseña saberes propios de la cultura, y otro espacio, externo a la comunidad, de amenaza, para el que los niños deben ser preparados. Si no hay tolerancia, menos aún tiene sentido el rescate. Por eso, la entrevista releva el rescate como discurso vacío, como evidencia de una suerte de apartheid, si no legal, instaurado implícitamente en las relaciones cotidianas que la educación intercultural no logra superar: "Entonces ¿De qué hablamos? ¿De qué rescate hablamos?”.

${ }^{20}$ Lo de "netamente mapuche", alude a un esencialismo del directivo-docente que sólo reconoce y legitima "razas puras". Desde este posicionamiento no cabe aceptar la existencia actual del pueblo mapuche, el que al mezclarse habría "perdido" históricamente su "esencia original" y con ella su derecho a reclamar una identidad otra.
} 


\section{Pilar Álvarez-Santullano, Ana Alves, Amílcar Forno, Rita Rivera, Pedro Fuenzalida}

Otro cuestionamiento de este director, se relaciona con la existencia actual de marcadas discriminaciones hacia los mapuches, las que sitúa en el pasado y no sólo como problema que afecte al mundo mapuche

Yo pienso que cualquier persona mayor que ella, si le preguntan cuál fue su situación en la escuela, posiblemente siempre le va a hablar de alguna discriminación... ¿No es cierto?, entonces aquí..., porque aquí en estas comunidades también puede hacer una entrevista a una persona de unos 40 , 45 años, 50 años y ellos le van a decir que sí, [que] en las escuelas sufrieron discriminación y diferentes tipos de discriminaciones... (TR-Ru-1).

El dispositivo puesto en juego permite a la vez que, casi al final de la reunión, la docente mapuche que había permanecido en silencio, releve su subjetividad y aporte el relato de su propia experiencia respecto de la discriminación

(...) quizás los que estamos metidos en temas de educación intercultural, digámoslo, esto no pasa, pero sí pasa en otros servicios públicos, por ejemplo, pasa la parte de la discriminación y tengo un ejemplo, el otro día mismo cuando fuimos al desfile mi hija no quería ir vestida de mapuche (...) Y después nosotros le dijimos no (...), si no hay nadie más en la escuela - le dije yo- - y yo estoy trabajando en la escuela, deberías ir porque si la escuela tiene algo que la diferencia es justamente que estamos trabajando la educación intercultural, pertenecemos a una comunidad mapuche. Le hicimos ver en la casa que si ella iba a ir con uniforme iba a parecer una escuela cualquiera no más ¿Ya?, pero ya en un momento, no feliz, [pero] ya se convenció, se fue vestida [de mapuche] (...) (TR-Ru-1).

Las experiencias de concreción curricular en las escuelas con EIB están permeadas por las políticas del saber-ser y saber-convivir que reclaman de sus actores sociales: directores, docentes, alumnos, familias. El discurso de la no discriminación se instala como el ideal, como las acciones pedagógicas y sociales políticamente correctas que un establecimiento intercultural debe representar. Son representaciones de este tipo los que se anidan en el imaginario de la asesora mapuche, que la llevan a motivar a su hija para asistir a la ceremonia del desfile. Todos juegan a la inclusión. Todos simbolizan la riqueza que implica reconocer la diferencia (en su deseo, ella también). Si los actos y comportamientos de la escuela EIB, no se transfieren a los actos y comportamientos de la comunidad, tenemos solamente EIB ideal y no EIB real. La continuidad del relato de la docente mapuche, devela la actualidad de la discriminación

"pero ya en un momento yo igual me sentí mal cuando un grupo de niñitos dijeron "mira los teñí, teñ̂l" y se rieron de ella dos... porque iba vestida de mapuche y "mira las teñ̂́, teñ̂l" dijeron, mira las indiecitas, entonces ella me miró y se enojó y me miró con una mirada y yo le dije qué pasó y me dijo “¿Escuchaste lo que dijeron?" y me dijo "¿Viste que todavía se burlan de nosotros? entonces ¿Que sacái?” — me dijo—, "tú, yo..., estoy bien — me dijo-, estoy súper clarita 
-me dijo-, me gusta ser mapuche, quiero ser mapuche, pero allá, pero yo vengo acá - me dijo —, y sufro la discriminación. Mira como se ríen de mí —me dijo-(TR-Ru-1).

Al exteriorizar su vivencia, la asesora cultural contrarresta la expresión hegemónica del poder-saber del docente directivo. Sin embargo, lo hace mediante una actuación que podemos llamar ponderada, probablemente, porque evalúa los riesgos posibles de una interpelación más directa (discursivamente, las dos primeras líneas de su intervención operan como atenuante para la posición del docente). El docente directivo no reacciona de inmediato ante esta intervención, sólo más tarde argumenta, reafirmando su posición inicial

(...) porque ese sentido de discriminación (...), por supuesto que se ha dado por siglos ¿No es cierto? desde los chilenos hacia los mapuches, pero la discriminación no es solamente eso, porque hay discriminación en todo sentido, en las clases sociales... Por ejemplo, en ese texto aparece (...) una persona que llevó a su papá a un hospital ¿No es cierto? con manta, pero no es porque era solamente mapuche, porque si es un campesino que no es mapuche le va a pasar lo mismo... Entonces ahí es donde tiene que haber el reforzamiento de ustedes como madre, uno como profesor entregarle a esos niños que no sólo por hecho de ser mapuche él sufra, a lo mejor así esos gritos que le pegaron a ella... porque suponte que a lo mejor pasan estos pokemones, igual les van a gritar tonteras por el pelo, por la forma de vestirse. Es una discriminación también, entonces... (TR-Ru-1).

El sentido que ha tenido la EIB, se refleja en la expresión de este docente: naturalización, homogeneización y determinismo. Su discurso pone continuamente de relieve, argumentos que simplifican el relato del conflicto, con lo que queda descontextualizado, en el sentido de que se omiten las explicaciones provenientes del contexto socio-histórico y político que le dio origen: "qué pasó, cómo pasó y fundamentalmente por qué pasó" (Carretero 2010:119). A diferencia de lo que ocurrió en el otro taller con el dispositivo del texto de Birgin, no hay aquí intermitencia; el profesor sustenta su posición confrontando el campo experiencial de las asesoras culturales, cuestionando incluso la representatividad y posibilidad de generalización de lo argumentado

Sería interesante saber lo que..., o sea, estas mismas preguntas, realizárselas a otras asesoras de otras comunidades... no solamente del sector de allá... (...) Claro, porque a lo mejor las realidades son diferentes (TR-Ru-1).

En resumen, el docente directivo niega la posibilidad de un proyecto de nación multicultural y, asimismo, la discriminación como fenómeno recurrente y actual e, incluso la representatividad de la entrevista analizada, por tratarse de lo señalado, sólo, desde un lugar determinado. Su argumentación no hace más que desconocer un posible currículo indígena, planteado por las asesoras; un currículo que reconozca el derecho que tiene el otro a ser visibilizado, y a relevar su condición cultural y 


\section{Pilar Álvarez-Santullano, Ana Alves, Amílcar Forno, Rita Rivera, Pedro Fuenzalida}

sociopolítica. Dos modos de concebir la educación intercultural aparecen en disputa: uno, contenido en la entrevista en que se interpela la concepción actual de la EIB, que abre un espacio en el aula para subvertir el discurso enmascarador de la tolerancia y el rescate, develando sus limitaciones, reposicionándolo como conocimiento situacional sobre el cual resulta necesario advertir a los alumnos; y otro, que reacciona frente a esta propuesta y que relega la EIB a un espacio limitado a contenidos y temas que no pongan en riesgo el proyecto nacionalista de una chilenidad hegemónica.

Comentarios metodológicos. El dispositivo de la entrevista aportó narrativas que fueron puestas en cuestión por un docente directivo, quien se ubica finalmente fuera de la problemática y de la realidad mapuche local. La asesora cultural afirma la existencia de la discriminación en el pasado, para luego situarla con fuerza en el "aquí" y el "ahora", mediante la narración de una experiencia personal reciente. El otro logro es que la docente mapuche logra, a través de la narración de su experiencia, y reafirmada en el relato de otra asesora cultural, sacar la voz - aunque todavía sutilmente - para dar cuenta de la incompletud del currículum de la EIB para el mundo de la vida.

\section{REFLEXIONES FINALES}

Hemos presentado una descripción y aproximaciones analíticas a lo que, desde nuestra perspectiva como investigadores, fue mostrándonos el trabajo de campo focalizado en los talleres, trabajo que “(...) exige un proceso permanente de 'desaprender', de mirar de nuevo, de dejar en suspenso lo que sabemos y nos ha servido para otras situaciones (...)” (Blanco 2005:375).

Se ha dicho que el currículum está en continua construcción. Al respecto, observamos que si bien la vigencia de códigos y normas en la escuela favorece el ordenamiento de contenidos, actividades, roles y ciertos sentidos del currículum, esta coherencia puede, en algunos casos, llegar a ser alterada por los sujetos en su práctica docente -como ocurre especialmente con los docentes mapuches en las escuelas visitadas - aun cuando tal actividad va a estar vigilada, controlada por la misma dinámica de las prácticas institucionalizadas y percibidas como legítimas y eficientes. De allí, tal vez, las limitantes para el ingreso de saberes situados, como el discurso del autogobierno - promovido por algunos movimientos indígenas- o el del guillatún, como acto de resistencia para la recuperación de tierras.

Observamos, también, que lo que se "recupera" son "algunos aspectos" de la cultura mapuche, aquéllos que no presentan contradicción con los valores que en la cultura occidental y cristiana hoy se reconocen como valiosos, por ejemplo, el "respeto por los ancianos", "la relación con la naturaleza". Se trata de aquellos saberes que podría decirse, son "confluyentes" con el discurso de la EIB; un discurso marcado por el respeto y la tolerancia, donde los conflictos, si aparecen, lo hacen "diluidos". De este modo, la educación intercultural repite el modelo de la escuela tradicional, que parece discurrir paralelamente a la circulación de las relaciones de poder en la sociedad mientras las sustenta y legitima. 
En este contexto, pocas veces ingresan saberes situados, y cuando ello ocurre, lo hacen estratégicamente, por los bordes, por los márgenes; o bien, se introducen como conversación fugaz respecto de alguna circunstancia ineludible por su impacto. La teatralización escolar, que usa la parodia como recurso para presentar los procesos de despojo de tierras, da cuenta de lo primero. Cuando en una clase se trata la noticia de la muerte de un comunero mapuche, se lo hace del modo aludido en segundo lugar. El traspaso de la herencia cultural del pueblo mapuche no ocurre como parte de una narrativa histórica en la escuela. No hay en ello una proyección, una "transmisión lograda" en términos de Hassoun (1996), que permita la recreación del legado por parte de quien lo recibe.

Estas conclusiones, por un lado, nutren parte de nuestras hipótesis, dando cuenta de "espacios y tiempos de "densa interculturalidad", donde la concreción del currículum resulta del cruce de acuerdos, consensos, adhesiones; pero también de desacuerdos, fracturas, desconocimiento, que a su vez, expresan intereses y legitimaciones de diferentes personas, grupos o sectores" (Alves, 2004:122).

Queremos, también, apuntar algunas notas reflexivas y conceptuales que consideramos aportan a la problematización del mismo objeto de nuestra investigación. Muy probablemente, el hecho mismo de "darnos la posibilidad" de reconocernos desde una perspectiva performativa (constructora de sentido) como investigadores, sea lo que posibilita estos comentarios.

- Hemos descrito formas viejas y nuevas, formas "otras", en que la institución escolar crea y re-crea las relaciones interculturales, en que los patrones institucionales posibilitan o no posibilitan el reconocimiento de los mapuches como sujetos portadores de saberes y experiencias, con capacidades y derechos. Resulta entonces necesario reflexionar acerca de la construcción escolar de saberes ligados a la cultura mapuche y a las relaciones interculturales en la sociedad chilena.

- En directa relación con el punto anterior, queremos destacar como aporte conceptual el reconocimiento del carácter performativo del lenguaje, considerándolo como un elemento central para el análisis de los discursos de los docentes, ya que, según Austin (1982), los actos performativos deben ser considerados en términos de su eficacia, de su éxito o fracaso, y de los efectos que producen. Podríamos parafrasear a Southwell, en el sentido de que "en el caso que nos ocupa, se trata de la producción de sujetos, es decir, la constitución de los sujetos como efectos de la significación de los discursos sociales, que constituyen entramados significativos, que interpelan a los sujetos a través de distintos "tipos" subjetivos, constituyéndolos (joven, alumna, excluido, delincuente, etc.). La interpelación, como forma de nominación, produce al sujeto, estableciendo las coordenadas de su identificación y, por lo tanto, de su posicionamiento (y existencia) en la red de relaciones que estructuran lo social. La interpelación no se dirige a un sujeto que ya existe con anterioridad a este acto, sino que lo produce en su misma operación. El mismo gesto que nos "ubica" en el entramado de la significación social, nos inviste de un poder para ser y hacer. Nos constituye en la 
existencia social, y nos habilita para poder hacer desde ese posicionamiento" (Southwell, 2008:27).

En definitiva, los talleres han permitido aproximarnos a la dinámica de los discursos de los maestros, a sus persistencias e intermitencias, y a los silencios e interpelaciones de los y las docentes mapuches. Junto con ello, hemos atisbado los espacios por los que circulan saberes proscritos, hemos sido testigos de la reafirmación de la identidad de los asesores culturales, cuando escuchan las voces de otros como ellos. Nuestra reflexión final apunta a que es imprescindible que en la escuela se genere una profunda reflexión, en la que la voz de los docentes mapuches es ineludible, y a que se transparenten y confronten los discursos ocultos, cuyos significados y valores, sin duda, son proyectados en el escenario curricular y, muchas veces, configuran verdaderas tramas de poder o de negociaciones en la micro-política de las escuelas.

\author{
Universidad de Los Lagos* \\ Departamento de Humanidades y Arte \\ Departamento de Educación \\ Avda. Alcalde Fuschlocher1305. Osorno (Chile) \\ palvarez@ulagos.cl,aforno@ulagos.cl \\ rriveraf@ulagos.cl,pfuenzal@ulagos.cl \\ Universidad Nacional del Comahue** \\ Facultad de Ciencias de La Educación \\ Yrigoyen 2000, C. P. 8324, Cipolletti. Río Negro (Argentina) \\ Analves2004@hotmail.com
}

BIBLIOGRAFÍA

Alvarez-Santullano, Pilar. Forno A. Rivera R. "La educación intercultural en el discurso directivo docente mapuche: posicionamiento desde los márgenes", en Patrimonio Cultural Mapuche (Teresa Durán et al. comp.). Vol II, 2007:283-295.

Alves, Ana M. Hacia una didáctica y un currículum en perspectiva intercultural. Buenos Aires: Universidad de Buenos Aires, 2004. Tesis de maestría no editada.

Antón Valero, José Antonio. "La pedagogía crítica desde la perspectiva de los movimientos sociales”. Versión electrónica del artículo publicado en Tabanque, $\mathrm{N}^{\mathrm{o}} 17$, incluido en Los movimientos de Renovación Pedagógica y la transformación socioeducativa. Vadallolid: Universidad de Valladolid, 2003.

Austin, John L. Cómo hacer cosas con palabras. Paidós: Barcelona, 1982.

Ball, S. La micropolítica de la escuela. Hacia una teoría de la organización escolar. Barcelona: Paidós/MEC, 1989.

Birgin, Alejandra. "La formación de los docentes: interrogantes y desafíos de nuestro tiempo". Ponencia presentada al Congreso Los significados de la Educación del Siglo XXI, 2006. http://weblog.mendoza.edu.ar/m_docente/archives/012061.html 
Blanco García, Nieves. "Innovar más allá de las reformas: reconocer el saber de la escuela", en REICE Revista Electrónica Iberoamericana sobre Calidad, Eficacia y Cambio en Educación, Vol 3. № 1. 2005.

Carretero, Mario; José A. Castorina. La construcción del conocimiento histórico. Enseñanza, narración e identidades. Buenos Aires: Paidós, 2010.

Corazza, Sandra. "Planejamiento de ensino como estratégia de política cultural", en Currículu: Questões athuais, (Varios autores). Brasil: Papirus editora, 1997.

Díaz, Raúl. Trabajo docente y diferencia cultural. Lecturas antropológicas para una identidad desafiada. Buenos Aires: Miño y Dávila editores, 2001.

Díaz, Raúl; G. Alonso. Construcción de espacios interculturales. Buenos Aires: Miño y Dávila editores, 2004.

Edwards, Verónica. "El conocimiento escolar como lógica particular de apropiación y alienación", en Cuadernos Políticos, 1986.

Forno, Amílcar; Álvarez-Santullano Pilar.; Rivera, R. "Entre el edificio y el currículum de la interculturalidad: una mirada antropológica a la educación actual en territorio mapuche-huilliche", en Chungará: Revista de Antropología Chilena, Vol. 41, № 2. 2009:287-298.

Escobar, Arturo. "Culture sits in places: reflections on globalism and subaltern strategies of localization". ("La cultura se sienta en lugares: reflexiones sobre el globalismo y las estrategias subalternas de localización)", en Political Geography N ${ }^{\circ}$ 20. 2001:139-174. (Citado en Gustafson, 2004).

Giglia, Angela. Pierre Bourdieu y la perspectiva reflexiva en las ciencias sociales, en Desacatos, primavera, $\mathrm{N}^{\circ}$ 011. 2003:149-160. Centro de Investigaciones y Estudios Superiores en Antropología Social. Distrito Federal. México.

Giménez, Gilberto. La sociología de Pierre Bourdieu. (Consultado: Febrero 1 del 2010). http://www.paginasprodigy.com/peimber/BOURDIEU.pdf

Gustafson, Bret. "El concepto de "red" y los conocimientos indígenas en la EIB". Revista Qinasay Ns. 1(2). (2004).

http://www.artsci.wustl.edu/ bdgustaf/gustafson2004_redes_de_saber.pdf

Gvirtz, Silvina; Larripa S.; Orí, A. Prácticas discursivas pedagógicas, didácti-cas y escolares: algunas categorías para repensar la relación entre el saber y la escuela. (s/f) http://www.fundacionluminis.org.ar/articulos/Practicas\%20discursivas\%20pedagogi cas, $\% 20$ didacticas\%20y\%20escolares.pdf.

Hassoun, Jacques. Los contrabandistas de la memoria. Buenos Aires: Ediciones de la Flor, 1996.

Pinto Contreras, Rolando. El currículo crítico. Una pedagogía transformativa para la educación latinoamericana. Santiago de Chile: Universidad Católica de Chile, 2008.

Scott, James C. Los dominados y el arte de la resistencia. Txapalarta, País Vasco: Editores Independientes, 2003.

Southwell, Myriam. "Hacer escuela con palabras: directores de escuela media frente a la desigualdad", en Archivos de Ciencias de la Educación. Año 2 - № 2 (2008) $4^{a}$ Época. La Plata: Universidad Nacional de La Plata.

Vera Godoy, R. Orientaciones básicas de los talleres de educadores. Santiago: Mimeo, 1985. 
------ Seminario "El taller de educadores, una herramienta conceptual y metodológica para el análisis de la propia práctica": Buenos Aires, 2008.

Walsh, Catherine. “(De) Construir la interculturalidad. Consideraciones críticas desde la política, la colonialidad y los movimientos indígenas y negros en el Ecuador", 115142, en Fuller, Norma. Interculturalidad y Política. Desafíos y posibilidades. Lima: Red para el Desarrollo de las Ciencias Sociales en el Perú, 2002. 